\title{
Development of regulatory framework in field of restoration materials
}

\author{
Jurij Pukharenko ${ }^{1}$, and Irina Aubakirova ${ }^{1, *}$ \\ ${ }^{1}$ Saint Petersburg State University of Architecture and Civil Engineering, St. Petersburg, Russia
}

\begin{abstract}
The restoration of historical objects allows you to save and recreate cultural monuments for the present and future generations. The work provides information on the restoration process, restoration materials, principles of scientific restoration. Based on the example of dry building mixes and ceramic decor, the classification of restoration materials is given and the main technical properties are highlighted, the need for standardization of these materials with the involvement of specialists in the field of building materials science is shown. It is shown that general construction quality indicators do not fully reflect the requirements of restoration materials in terms of reproducing the authenticity of material and technology. A review of the regulatory framework in the field of restoration, including federal laws, codes of restoration rules, interstate, national and international standards, is given. The features and directions of the further development of standardization in the field of restoration materials are highlighted.
\end{abstract}

\section{Introduction}

The main goal of protecting cultural monuments is to preserve the object of cultural heritage for a long time.

Restoration is defined as a set of measures aimed at preventing subsequent destruction and achieving optimal conditions for the long-term preservation of monuments of material culture (individual architectural structures and their complexes, works of fine and decorative art, archaeological finds, etc.).

Unlike repair, the restoration of architectural monuments is based on the results of their comprehensive scientific research and is carried out by special methods different from the practice of modern construction.

Today, the restoration of architectural monuments is a rather laborious process. According to Art. 47 of the Federal Law "On Objects of Cultural Heritage of the Peoples of the Russian Federation" [1] restoration of an architectural monument is a way of its reconstruction. Article 43 states that for this purpose research work, surveys, design and production work should be carried out for the maximum safety of structures of historical significance. Restoration in architecture restores and strengthens structures. As materials for strengthening the structure, those that are close to the original are used, methods are applied that will not damage the structure. In the process of restoration, damaged parts are restored, dam-

* Corresponding author: centeririna@spbgasu.ru 
aged or contaminated surfaces are cleaned, and add-ons and additions made in later periods are removed.

GOST R 56891.2-2016 "Preservation of objects of cultural heritage. Terms and Definitions. Part 2. Monuments of history and culture" [2] gives the following definition of the term "Restoration of a monument or ensemble" - research, research, design, production work carried out in order to identify and preserve the historical and cultural value of a cultural heritage object.

One of the most important principles of scientific restoration is the principle of minimal interference with historical material. The foundations of scientific restoration were laid in May 1964 at the International Congress of Architects and Technical Specialists in Historical Monuments and officially entitled the "International Charter for the Conservation and Restoration of Monuments", also known as the "Venice Charter".

The development of practical and theoretical activities has given rise to three basic methods, the essence of which is expressed by the three Great Ideas of restoration:

the first is the restoration of the work in its original form;

the second is the preservation of the facility in the highest possible integrity;

the third is the identification and coordination of the historical and artistic values of the object.

In accordance with these concepts, the basic principles of restoration and conservation are formulated:

- minimal interference in the historical material of the work with its maximum preservation;

- the validity and definition of any restoration intervention;

- scientific;

- historicism;

- legal regulation of relationships in restoration activities.

The most important principle of scientific restoration is the principle of minimal interference with historical material, the basis of which is laid down in the Venice Charter of restorers: "... for the monument, the most correct is the study, restoration and use of historical technologies."

The works of many authors [3-7] provide information about the materials used for the restoration of historical objects, but there is no information about the regulatory support of these products. In addition to domestic specialists, foreign companies are also present on the restoration market with their own materials, and accordingly with their inherent requirements set forth in international standards, for example, ASTM C 1713-15 "Standard Specification for Mortars for Repair of Historic Masonry", ASTM C 1722- 11 "Standard Guide for Repair and Restoration of Dimension Stone" [8, 9]. However, these standards or their elements are not included in the Russian regulatory framework.

Thus, the relevance of this study is related to the problems of the inadequacy of the regulatory framework in the field of restoration materials, the need for its updating to carry out the conservation of architectural monuments.

Object of study - monuments of architectural heritage, a system of regulatory documents in the restoration.

The subject of the study is restoration materials as objects of standardization.

The aim of the work is to study the regulatory framework in the field of restoration materials.

In accordance with the goal, the following research tasks were identified: identifying the features of building materials used in restoration, comparing the regulatory support of restoration materials with existing building materials science standards and identifying areas for further work on their standardization and conformity assessment. 


\section{Results and discussion}

Today on the market of restoration materials there is no common understanding both regarding terminology and requirements for technical properties of materials.

According to the GOST R project "Preservation of Stone Architecture Monuments" (Section 4.11) [10], all restoration materials used in the preservation of cultural heritage objects have general requirements for the compatibility of physical, mechanical and chemical properties with properties genuine materials of the object of cultural heritage, and, if necessary, the identity of decorative and artistic properties.

Given the wide variety of tasks performed during restoration, it is important to determine the key requirements for the materials and ensure the unity of the test methods. Filling the regulatory framework with standards that establish requirements for restoration materials and test methods will allow specialists performing restoration work to choose the "right" material, and conformity assessment bodies to give objective conclusions about the compliance of the materials used with the established requirements.

Restoration work is carried out using both traditional building materials similar to those used in the construction of the monument, or similar in physical, mechanical, chemical and decorative properties, as well as modern composite materials used to supplement and restore the restored parts, as well as specially developed materials for protection against various influences. All restoration materials have general requirements for the compatibility of physical, mechanical and chemical properties with the characteristics of genuine historical material and the identity of decorative indicators.

One of the main requirements for restoration is the maximum co-preservation of the authenticity of the object. Therefore, the replacement of damage is an extreme measure, it is advisable to use special methods of reinforcement. For each object of cultural heritage, a restoration method is selected based on knowledge of the building technology of the past and the ability to reproduce it with the necessary degree of approximation by modern methods.

The main factors causing the destruction of cultural monuments can be divided into two groups: external, associated with environmental influences and lack of proper care, and internal, due to the structure of the material, its chemical composition, physicomechanical properties and design features. Depending on the condition of the object of cultural heritage, various restoration methods are used: conservation, rearrangement, replacement of lost fragments, imitation of individual elements (separately or simultaneously).

Dry building mixes, which are widely used in the restoration of monuments of stone architecture, correspond to all of the above goals. The definition and classification of dry restoration mixtures appeared in 2015 in the second edition of the interstate standard GOST 31189-2015 "Dry building mixes. Classification" [11]. According to this standard, restoration mixtures are materials that provide:

1) compliance with the mechanical properties of the restored object,

2) the authenticity of the composition of the mixture,

3) compliance with the appearance of the restored object /

Restorative dry mixes are classified

by appointment to:

- masonry,

- plaster

- for restoration of natural stone and brick.

by type of binder:

- calcareous,

- lime-pozzolanic,

- lime-gypsum, 
- based on romance,

- based on hydraulic lime,

- gypsum,

- cement.

The technological and operational characteristics of restoration materials differ significantly from the properties of conventional building materials. Restoration materials must have both decorative and technical properties, be water-, weather-resistant, strong and durable, allow the structure to "breathe", not crack, and not tear off from the surface on which it is applied. Using the QFD methodology - Quality Function Deployment (deployment of the quality function - the "home" of quality) [12], these customer wishes can be translated into product quality requirements (technical properties of the material), which are subsequently formed in the regulatory literature (GOST, STO, technological regulations, etc.).

The main physical and mechanical parameters of dry restoration mixtures:

- mobility (plasticity);

- time to maintain mobility;

- strength (under compression, bending, stretching);

- average density;

- vapor permeability;

- adhesion to the base (concrete, brick, stone, etc.);

- frost resistance of the material;

- frost resistance of the contact zone;

- water absorption during capillary suction;

- crack resistance;

- shrinkage / expansion / swelling;

- corrosion resistance;

- biostability;

- material composition.

The listed characteristics should be taken into account when designing technical requirements for restoration materials. In restoration projects indicate the approximate composition of the material, which can not always provide the required technical and operational properties. The properties of materials depend on the material composition and structure, manufacturing technology, which may contradict the principles of restoration. If, due to the loss of historical technologies or for any other reasons, it becomes necessary to use new materials, one should remember to exclude the possibility of violating the historical appearance of the monument.

Modern dry mixes can be used for restoration of facade and interior plasters, for sanitation of building envelopes, for decorative finishing of facades and drawn decorative elements, for restoration of floor coverings, stairs, basement cladding, repair of masonry, tiles, stone reinforcement and as a stone substitute.

When using dry restoration mixtures, it is necessary to take into account the relationship between the manufacturer of the mixtures and the manufacturer of the work. The research approach and analytical methods for studying the cultural monument allow the manufacturer of dry mixes to design, produce and test the finished product, but this product life cycle requires significant time and labor costs. Especially lengthy are tests to confirm the resistance of the material to various influences (frost resistance, corrosion resistance, biostability, etc.). Both physico-mechanical and chemical compatibility should be verified. Typically, mechanical compatibility is easily checked by indicators of density, strength, vapor permeability. Chemical compatibility should ensure the absence of any interactions with existing structures (masonry, plaster mortars). Some difficulties in the process of development and production of authentic material are the selection of raw materials. It is especially difficult to choose an astringent that ensures the achievement of the necessary indicators. 
The main astringent for restoration dry mixes is air lime. From ancient times, various additives, such as rice paste and tung oil (Ancient China), decoction of spruce bark, cottage cheese, egg white, flaxseed oil, bovine blood (Ancient Russia), were used to improve the properties of lime solutions. Modern modifying additives (silica fume, metakaolin, nanostructured components) make it possible to obtain lime solutions that are close in properties to the true historical compositions. All these modified binders require legal implementation in production through the standardization process at least at the enterprise level.

Analyzing the regulatory framework of modern materials science, it should be noted that it lags behind international standards. A striking example of this is the process of updating the national standard for building lime. Existing standards GOST 9179-77 "Building lime. Specifications "and GOST 22688-77" Building lime. Test methods" in 2018 did not change the content, but the year of review. While the European standard EN 459 "Building lime - Part 1: Definitions, specifications and conformity criteria" [13] classifies lime into 4 classes: CL / DL - calcium / dolomite air, NHL - natural hydraulic lime without additives, NHL- Z - natural hydraulic lime with additives (up to $20 \%$ pozzolanic hydraulic additives), HL - hydraulic lime (artificial, may contain ash, cement, etc.). Moreover, each class of lime has several grades (for example, NHL2, NHL3.5, NHL5). The lack of more modern nomenclature and quality indicators in Russian standards allows an unscrupulous supplier to mislead dry mix manufacturers - participants in the restoration market.

The existing system of national standards in the field of general building materials and products is insufficient to standardize requirements for restoration materials and subsequent confirmation of their compliance.

Another example of a discussed regulatory document developed in 2019 and undergoing a public review stage is the draft standard "Preservation of Stone Architecture Monuments. Ceramic decor" [14]. This project applies to ceramic products for various purposes: wall (brick, facade tiles), roofing (tiles), decor for exterior and interior (tiles) and divides all architectural ceramics into two types: terracotta and majolica. The main content of the draft standard is devoted to the technology of manufacturing tiles: the manufacture of a gypsum model of tiles, the removal of plaster casts, the drawing of relief using clay, the preparation of ceramic mass, the technology of molding, drying, firing, glazing. The finished product was presented with indicators of the appearance of the glaze coating of tiles (there should be no "flies", "cuts", "clogging", "blowing", "burning out", boiling and dryness) and the requirements for water absorption were set within 6-14\%, frost resistance - not less than 25 cycles of freezing and thawing, compressive strength - not less than $150 \mathrm{~kg} / \mathrm{cm}^{2}$ and tensile strength in bending - not less than $70 \mathrm{~kg} / \mathrm{cm}^{2}$. These requirements cannot characterize the quality of all ceramic products included in the scope of this draft standard, do not provide methods for determining these indicators and criteria for their evaluation, and, obviously, this document will not be possible to use in restoration work. The reason for this discrepancy is that the specialists in the field of building materials science were not involved in the development of the project, there is no terminological, standardization, or metrological expertise.

Restoration rulemaking developed in parallel with standardization in the construction industry, first under the leadership of the Ministry of Culture, and subsequently the Technical Committee for Standardization No. 82 "Cultural Heritage" in the context of departmental fragmentation. As noted in [15], builders have SNiP, and restorers have RNiP.

The implementation of works on preservation of cultural heritage at different times was regulated by the following regulatory documents:

- RNiP 1.02.01-94 (Restoration Norms and Rules) "Instructions on the composition, procedure for the development, coordination and approval of scientific and design documentation for the restoration of immovable historical and cultural monuments"; 
- PSA - 2007 (Code of Restoration Rules) "Recommendations for research, survey, design and production work aimed at preserving cultural heritage objects (historical and cultural monuments) of the peoples of the Russian Federation" (in 4 editions).

Currently, the above documents have been canceled due to the introduction of a number of national standards relating to various stages of restoration work: from the development of scientific and design documentation to the terms and definitions in the conservation of cultural heritage: GOST R 55528-2013, GOST R 55567- 20013, GOST R 55627-2013, GOST R 55653-2013, GOST R 55935-2013, GOST R 55945-2014, GOST R 56198-2014, GOST R 56200-2014, GOST R 56254-2014, GOST R 56891.1-2017 ... GOST R 56891.62017. But all these regulatory documents do not take into account key indicators of the quality of restoration materials, international and domestic experience in this industry. Currently, almost all organizations produce restoration materials according to their own regulatory documents (standards of service stations organizations or technical specifications of $\mathrm{TU})$, using their own set of quality indicators and test methods, which affects the quality of the restoration as a whole.

\section{Conclusions}

Analyzing the state of the regulatory framework in the field of restoration materials, it was found that the "bottlenecks" of the modern restoration process in the field of standardization are as follows:

- requirements for materials and technologies are formed without conducting scientific research and without experimental confirmation;

- Russian laboratories are accredited to test modern building materials and therefore cannot give conclusions on the properties most important for restoration;

- there is no harmonization with international standards both in terms of technical properties and test methods.

The above provisions require the further development of the regulatory framework in the field of restoration materials with the participation of the entire professional community.

\section{References}

1. Federal Law No. 73 "On Objects of Cultural Heritage (Monuments of History and Culture) of the Peoples of the Russian Federation" dated 06.25.2002

2. GOST R 56891.2-2016. Co-storage of cultural heritage sites. Terms and Definitions. Part 2. Monuments of history and culture (Rosstandart, Moscow, 2016)

3. N.A. Kosenkova, I.S. Biryukov, Novosibirsk State University of Architecture, Design and Arts, Creativity and Modernity 5, 44-48 (2018)

4. I.L. Chulkova, Bulletin of SibADI 6(34), 66-72 (2013)

5. O.S. Subbotin, S.A. Bondarenko, University News. Construction 6, 97-105 (2018)

6. Yu.V. Pukharenko, A.M. Kharitonov, N.N. Shangina, Bulletin of civil engineers 1(26), 98-103 (2011)

7. Yu.V. Pukharenko, T.V. Kharitonova, Bulletin of Civil Engineers 4(69), 121-125 (2018)

8. ASTM International. Standard Specification for Mortars for Repair of Historic Masonry, ASTM, 1713-1715 
9. ASTM International. Standard Guide for Repair and Restoration of Dimension Stone, ASTM, 1722-1711

10. GOST R project Preservation of monuments of stone architecture. General requirements. http://docs.cntd.ru/document/554788317

11. GOST 31189-2015. Dry mixes for building. Classification (Rosstandart, Moscow, 2015)

12. QFD: Product and process development based on customer requirements and expectations. http://www.ssau.ru/files/education/metod_1/vashukov_qfd.pdf

13. European Committee for Standardization. Building lime - Part 1: Definitions, specifications and conformity criteria, EN 459-1: 2010

14. GOST R project Preservation of monuments of stone architecture. Ceramic décor. http://docs.cntd.ru/document/560602992

15. Yu.T. Komarov, Standards and quality 2, 46-50 (2010) 